\title{
DECISIONES FINALES EMITIDAS POR LOS PANELES DE SOLUCIÓN DE CONTROVERSIAS, ESTABLECIDOS EN EL MARCO DE LOS CAPÍTULOS XIX Y XX DEL TRATADO DE LIBRE COMERCIO DE AMÉRICA DEL NORTE DURANTE 2002*
}

Conforme al Artículo 2002 del Tratado de Libre Comercio de América del Norte (TLCAN), la Comisión de Libre Comercio ha establecido un secretariado integrado por tres secciones nacionales, cada una de ellas en las ciudades capitales de los países miembros del TLCAN. Su función es la de prestar asistencia y apoyo administrativo a la comisión, paneles, comités y grupos de trabajo establecidos conforme al propio tratado.

Durante el año 2002 se emitieron siete decisiones finales, de las cuales la emisión de dos de ellas fue administrada por la sección mexicana, como secretariado responsable; tres por la sección estadounidense y dos por la sección canadiense.

A continuación se presenta un resumen del sentido de cada una de ellas.

\section{SECCIÓN MEXICANA}

\section{Capítulo XIX}

Caso: Revisión de la resolución final de la investigación antidumping sobre las importaciones de jarabe de maíz de alta fructosa, originarias de Estados Unidos de América.

* Fuente: Sección mexicana del Secretariado de los Tratados de Libre Comercio. Para acceder a una versión completa de los textos de las decisiones finales, se puede acudir a las secciones nacionales del secretariado o visitar la página de Internet: http://www.nafta-sec-alena.org. 
Número de expediente: MEX-USA-98-1904-01.

Países involucrados: México y Estados Unidos de América.

Panel: Víctor Blanco Fornieles (México), Héctor Cuadra y Moreno (México), Howard N. Fenton (EUA), Saul L. Sherman (EUA) y Gustavo Vega Cánovas, presidente del panel (México).

Fecha de emisión de la primera decisión final: 3 de agosto de 2001. Se ordena devolver cuotas y suspender garantías o reponer procedimiento de conformidad con la misma decisión. El 30 de agosto de 2001, se emitió la corrección de la decisión final del panel. El 23 de noviembre de 2001, la autoridad investigadora presentó su Informe de Devolución. El 15 de abril de 2002, el panel emitió su decisión final sobre dicho Informe de Devolución, con la que devuelve nuevamente el expediente. El 15 de mayo de 2002, la autoridad investigadora emitió nuevamente un Informe de Devolución. El 18 de junio de 2002, el panel confirma este segundo informe y ordena al secretariado responsable emitir el Aviso de Acción Final del panel.

\section{Decisión final sobre el Informe de Devolución}

(15 de abril de 2002):

1. La autoridad investigadora tuvo múltiples oportunidades, tanto para revisar el material contenido en el expediente administrativo, como para ampliarlo, como resultado de la primera revisión dictada por el Grupo Especial del Órgano de Solución de Diferencias de la Organización Mundial de Comercio;

2. La autoridad investigadora, en dos ocasiones, no ha logrado demostrar ante este panel que el expediente administrativo sirve de base para llegar a la conclusión de que las importaciones de jarabe de maíz de alta fructosa, provenientes de Estados Unidos de América, importan una amenaza de daño a la industria mexicana del azúcar y a su mercado;

3. Conforme a las disposiciones del capítulo XIX del Tratado de Libre Comercio de América del Norte, la revisión por parte de un panel tiene que basarse exclusivamente en el expediente administrativo.

4. No existe fundamentación en el expediente combinado que resultó de la investigación original y de la investigación por la que la autoridad investigadora revisó su decisión original, que sustente la conclusión de que las importaciones de jarabe de maíz de alta fructosa, provenientes de Estados Unidos de América, significan amenaza de daño para la in- 
dustria mexicana del azúcar, lo cual hace que las tres decisiones adoptadas por la autoridad investigadora sean inconsistentes con las disposiciones internacionales y legales que las rigen.

5. Como resultado de esta determinación, este panel también determina que la imposición y el cobro de las cuotas compensatorias impuestas a las importaciones de jarabe de maíz de alta fructosa originarias de Estados Unidos de América, han sido y continúan siendo inconsistentes con las disposiciones internacionales y legales que las rigen, puesto que fueron el resultado de una conclusión de la autoridad investigadora, relativa a la amenza de daño, que es inconsistente con las disposiciones internacionales y legales que la rigen.

6. En consecuencia ordena lo siguiente: Este panel devuelve este asunto a la autoridad investigadora para que en un término no mayor de treinta días, contados a partir de la emisión de esta orden, actúe de manera consistente con la decisión que este panel adopta de que la imposición y el cobro de las cuotas compensatorias impuestas a las importaciones de jarabe de maíz de alta fructosa originarias de Estados Unidos de América, son inconsistentes con las disposiciones internacionales y legales que las rigen.

Caso: Revisión de la resolución final de la resolución antidumping sobre importaciones de urea procedente de Estados Unidos de América y la Federación Rusa.

Número de expediente: MEX-USA-00-1904-01.

Países involucrados: México y Estados Unidos de América.

Panel: Raymundo Enríquez (México), Peggy Chaplin (EUA), Michael Gordon (EUA), Leonard Santos (EUA) y José Francisco Contreras Vaca, presidente del panel (México).

Fecha de emisión de la decisión final: 4 de mayo de 2002.

\section{Decisión final:}

1. El panel ordena devolver la resolución final a la Secretaria de Economía, con el fin de que la autoridad investigadora emita la resolución final que corresponda en consistencia con lo expuesto en la decisión, particularmente lo establecido por Agromex donde reclama la supuesta ilegalidad de la determinación de la SE de concluir el procedimiento administrativo de investigación sin imponer cuota definitiva alguna, bajo la 
consideración de que, al momento de la emisión de la resolución final, Agromex había perdido el carácter de productor nacional y que, por consecuencia, carecía de legitimación procesal activa en el procedimiento de investigación.

2. En términos generales, Agromex sostiene que no existe motivación ni fundamentación legal alguna, con base en las cuales la SE pudiera haber apoyado su determinación de concluir la investigación en cuestión, de acuerdo con la supuesta carencia de legitimación procesal activa, derivada del hecho incuestionable de que al momento de la emisión de la resolución final, Agromex no producía urea (y en consecuencia, no se le podía considerar como productor nacional).

3. En soporte a su argumento, Agromex destaca el hecho de que la propia SE había reconocido previamente su carácter de productor nacional, tanto en la resolución de inicio como en la preliminar.

4. En general se adopte cualesquiera medida no incompatible con la presente decisión, respecto de las importaciones de urea, mercancía clasificada en la fracción arancelaria 3102.10.01 de la Tarifa del Impuesto General de Importación, originarias de Estados Unidos de América, independientemente del país de procedencia.

\section{Capítulo $X X$}

No se integró ningún panel en el marco del capítulo XX del TLCAN.

\section{SECCIÓN ESTADOUNIDENSE}

\section{Capítulo XIX}

Caso: Cemento Gray Portland y Clinker procedente de México (7a. Revisión Administrativa).

Número de expediente: USA-MEX-99-1904-03.

Países involucrados: Estados Unidos de América y México.

Panel: Luois Mastriani, presidente del panel (EUA), Mark Joelson (EUA), Steven Zamora (EUA), Ruperto Patiño Manfer(México) y Gustavo Vega Cánovas.

Fecha de emisión de la decisión final: 30 de mayo de 2002. 


\section{Decisión final:}

El panel devuelve al Departamento de Comercio y confirma las siguientes cuatro conclusiones del mismo en su resolución definitiva:

1. Que las ventas de Cemex en el mercado doméstico de cemento, que es físicamente de tipo $\mathrm{V}$, como de tipo II y tipo $\mathrm{V}$, fueron hechas fuera del curso ordinario del comercio.

2. Que un ajuste a los gastos de venta indirectos de CDC por intereses supuestamente incurridos al financiar depósitos en efectivo para cuotas compensatorias no es justificado.

3. Que recurrir parcialmente a la información negativa disponible para los datos de la planta de Hidalgo de Cemex (en lugar de utilizar en su totalidad la información negativa disponible para la respuesta de Cemex) es justificado; y

4. Que rechazar el revocar la resolución Antidumping por supuestos en el inicio de la investigación original LTFV, es justificado.

Este panel devuelve los siguientes aspectos al Departamento de Comercio:

1. Que las ventas en el mercado doméstico de Cemex de cemento tipo $\mathrm{v}$, vendido como tipo i, fueron hechas fuera del curso ordinario de comercio.

2. Que las cuotas deben asignarse sobre una base nacional, en este caso de industria regional.

3. Que el cemento en bolsa y en bulto de Cemex debe ser clasificado como el mismo producto similar, y que las ventas de cemento en bolsa y en bulto de Cemex fueron realizadas en el mismo nivel de comercio.

4. Que los gastos de almacenamiento en Estados Unidos de América de Cemex y Cemento de Chihuahua deben ser tratados como gastos de venta indirectos.

5. Que los gastos de almacenamiento por preventa en el mercado doméstico de Cemex no deben deducirse del valor normal.

6. Que ciertas ventas de Cementos de Chihuahua a clientes no afiliados en Estados Unidos de América por empresas filiales de Cementos de Chihuahua en Estados Unidos, deben clasificarse como ventas indirectas de precio de exportación, en lugar de ventas de precio de exportación reconstruido.

7. Que el ajuste Difmer a las ventas de Cemex por diferencias físicas entre el cemento tipo I y el tipo $\mathrm{V}$ fue justificado y

8. Que un ajuste por gastos de flete de Cemex fue justificado. 
Caso: Magnesio puro procedente de Canadá (Full Sunset Review).

Número de expediente: USA-CDA-00-1904-06.

Países involucrados: Estados Unidos de América y Canadá.

Panel: Charles Owen Verrill, presidente del panel (EUA), Donald Brown (Canadá), Edward Chiasson (Canadá), Edward Farrell (EUA), Michael House (EUA).

Fecha de emisión de la decisión final: 27 de marzo de 2002.

\section{Decisión final:}

El panel remite este asunto al Departamento de Comercio para que reconsidere:

1. La pretensión de GOQs respecto a la buena causa bajo lo establecido en la sección 752 (C) (2) del reglamento; y

2. La determinación del reporte de la investigación de la tasa del margen de dumping con más probabilidad de prevalecer si la orden es revocada.

Caso: Magnesio puro y Aleación de Magnesio procedente de Canadá. (Full Sunset Review).

Número de expediente: USA-CDA-00-1904-07.

Países involucrados: Estados Unidos de América y Canadá.

Panel: Charles Owen Verrill, presidente del panel (EUA), Donald Brown (Canadá), Edward Chiasson (Canadá), Edward Farrell (EUA), Michael House (EUA).

Fecha de emisión de la decisión final: 27 de marzo de 2002.

\section{Decisión final:}

El panel por este conducto remite para reconsiderar los resultados finales del Departamento de Comercio de la siguiente manera:

1. La determinación de usar los resultados de la sexta revisión como tasa de subsidio para ser reportado al ITC;

2. La base para las otras empresas las demás tasas; y

3. Las razones de la falla en las investigaciones de subsidio alegados a favor de la empresa MAGNOLA.

\section{Capítulo $X X$}

No se integró ningún panel en el marco del capítulo XX del TLCAN. 


\section{SECCIÓN CANADIENSE}

\section{Capítulo XIX}

Caso: Ciertos aparatos domésticos.

Número de expediente: CDA-USA-00-1904-03.

Países involucrados: Canadá y Estados Unidos de América.

Panel: Warren Connelly (EUA), Jane C. Luxton (EUA), Serge Anissimoff, presidente del panel (Canadá), Anthony Halliday (Canadá), Paul LaBarge (Canadá).

Fecha de emisión de la decisión final: 15 de abril de 2002.

\section{Decisión final:}

1. El panel revisó los escritos y memoriales presentados por Whirlpool e Inglis, en relación a la decisión final; de igual manera ha tomado en cuenta los argumentos orales expuestos por Whirlpool e Inglis.

2. Tomando en consideración lo expuesto en cada uno de los argumentos presentados por dichas empresas en su escrito inicial referente a la decisión final y habiendo determinado, con respecto a cada argumento, que ninguna recomendación ha sido requerida, este panel desecha los argumentos con los que Whirlpool e Inglis iniciaron el procedimiento con fecha 11 de septiembre de 2000.

3. A la luz de las conclusiones de este panel, hechas en referencia a cada uno de los argumentos establecidos con anterioridad, el panel desecha los argumentos con los que se dio inicio este procedimiento, para Camco, Whirlpool e Inglis, y declina emitir una recomendación en cualquier sentido acerca de la decisión final.

Caso: Ciertos aparatos domésticos.

Número de expediente: CDA-USA-00-1904-04.

Países involucrados: Canadá y Estados Unidos de América.

Panel: Warren Connelly (EUA), Jane C. Luxton (EUA), Serge Anissimoff, presidente del panel (Canadá), Anthony Halliday (Canadá), Paul LaBarge (Canadá).

Fecha de emisión de la decisión final: 16 de enero de 2002. 


\section{Decisión final:}

El panel emitió su decisión final de la siguiente manera: Cuatro votos a favor y un voto concurrente. Por los razonamientos asentados, el panel por este medio ordena que la decisión de la autoridad investigadora en este asunto debe ser confirmada.

La opinión concurrente sostiene que encuentra algunas omisiones e implicaciones en el razonamiento del panel, donde determina que habría mayor crédito a cortes de revisión y a abogados con considerable mayor pericia en asuntos financieros y de regulación específica que el panel, por lo que en un balance observa que hay una "pericia relativa" en cuanto a la instauración del cuerpo revisor.

\section{Capítulo $X X$}

No se integró ningún panel en el marco del capítulo XX del TLCAN. 